\title{
Development of Resource-Saving Technologies in the Use of Sedimentation Inhibitors for Reverse Osmosis Installations
}

\author{
Inna Trus ${ }^{1 *}$, Mukola Gomelya', Margarita Skiba², Tetiana Pylypenko ${ }^{3}$, Tamara Krysenko ${ }^{1}$ \\ 1 Department of Ecology and Technology of Plant Polymers, Faculty of Chemical Engineering, Igor Sikorsky \\ Kyiv Polytechnic Institute, Peremogy Avenu 37/4, 03056 Kyiv, Ukraine \\ 2 Department of Inorganic Substances and Ecology, Faculty of Chemical Technology and Ecology, Ukrainian \\ State Chemical Technology University, Gagarin Ave. 8, 49005 Dnipro, Ukraine \\ 3 Department of Physical Chemistry, Faculty of Chemical Technology, Igor Sikorsky Kyiv Polytechnic Institute, \\ Peremogy Avenu 37/4, 03056 Kyiv, Ukraine \\ * Corresponding author's e-mail: inna.trus.m@gmail.com
}

\begin{abstract}
The processes of desalination of weakly mineralized waters using a reverse osmosis membrane were studied. The operational efficiency of membranes is limited mainly by membrane contamination. It was shown that the preliminary mechanical water purification helps to increase the productivity and selectivity of the membrane. One of the main causes of membrane contamination is the formation of carbonate deposits on their surface. One way to prevent membrane contamination is to dose antiscalants. It was established that the use of hydrolyzed polyacrylonitrile (HPAN) and hydrolyzed polyacrylamide (HPAA) as a stabilizer of scale formation is effective for concentrates of reverse osmosis desalination of water.
\end{abstract}

Keywords: reverse osmosis, concentrate, membrane, permeate, productivity, selectivity, antiscalant.

\section{INTRODUCTION}

Recently, in industrial densely populated areas, the problem of water pollution and a sharp increase in water mineralization of surface waters has become more acute (Biggs et al. 2015, Radovenchyk et al. 2021, Trus et al. 2017). This is caused by the discharge of mine and industrial wastewater, as well as effluents from thermal power plants (DiGiulio et al. 2015, Abualhaija and Mohammad 2021, Trus and Gomelya 2021). Today, the most highly efficient technologies for water desalination include baromembrane processes (Cohen et al. 2017, Ashfaq et al. 2019, Trus and Gomelya 2021). Reverse osmosis units provide high and guaranteed stable cleaning quality throughout the operation (Miller et al. 2015). The main task today is to achieve the maximum service life of membrane elements. The service life of membranes is determined mainly by the drop in their productivity, and the operational efficiency of membrane water treatment systems is limited mainly by their pollution degree (Da'na et al. 2020, Kucera et al. 2019, Yelemanova al. 2021).

At present, in water-deficient industrial regions, highly mineralized waters with high hardness are used in cooling systems (Filloux et al. 2015, Croué et al. 2013, Sweity et al. 2013, Trus et al. 2020). These waters are not suitable for use in cooling systems without special treatment (Yelemanova et al. 2021, Remeshevska et al. 2021, Trus et al. 2019). The use of effective stabilizers allows abandoning expensive water softening and deaeration systems, as well as ensuring long-term operation of heat exchange equipment. Despite the large number of studies, the stabilization of such waters to sediments is not a sufficiently explored question (Popov et al. 2019, Ang et al. 2016, Khan et al. 2013).

The main factor limiting the widespread use of reverse osmosis (RO) installations in drinking water production and industrial water treatment 
is the scaling of sparingly soluble salts (Golovesov et al. 2021, Chaussemier et al. 2015, Shemer et al. 2013).

In order to reduce the scale of gypsum and silicon dioxide, it is necessary to use antiscalants with different functionalities, so when cleaning wastewater containing different types of scale, it is important to select a reagent that provides maximum effect (Yin et al. 2021, Pramanik et al. 2017, Rashed et al. 2016, Mi and Elimelech 2013).

Phosphonate antiscalants are widely used in the processes of reverse osmosis desalination of water to prevent scale formation and improve the quality of purified water. In reverse osmosis desalination of groundwater at a sampling rate of $85 \%\left(\mathrm{Ca}^{2+}=765 \mathrm{mg} / \mathrm{L}, \mathrm{PO}_{4}^{3-}=13-15 \mathrm{mg} / \mathrm{L}\right.$ and $\mathrm{pH}=7.6$ ), various antiscalants were used to inhibit the formation of calcium phosphate. (Mangal et al. 2021). However, it is desirable to remove them before disposing of the RO concentrate, as the presence of phosphonate antiscalants can prevent the removal of hardness from the concentrates and affect the ecosystem. A highly effective magnetic adsorbent (magnetic $\mathrm{La} / \mathrm{Zn}$ / Fe3O4@PAC composite) can be used to remove the phosphonate antiscalant (Li, C. et al. 2021).

In (He et al. 2009) it was shown that the K752 antiscalant can significantly extend the induction period for the gypsum nucleation, while the GHR antiscalant extends the induction period for calcite nucleation; even at a dosage of only $0.6 \mathrm{mg} / \mathrm{L}$, they slow down the rate of crystal deposition. In (Qiang et al. 2013) it was shown that scale inhibitor was prepared by modified chrome shavings hydrolyzing collagen and the scale inhibitor had good ability on calcium carbonate scale inhibition.

The efficacy of scale inhibitors for a reverse osmosis desalination plant has been developed and evaluated (Chesters et al. 2009, Pervov \& Andrianov 2017). Adding antiscalants into the solution slows down the scale on the membrane, as evidenced by membrane flux, morphology and layer thickness (Chen et al. 2021).

Management of scale formation can be achieved at the design stage by the inclusion of unit processes to the scale forming constituents or by the application of the antiscalants that delay the onset of nucleation (Antony et al. 2011).

The developed methods of softening of a scale deposit mainly do not depend on membrane materials, whereas expediency of creation of the scaleresistant membranes is specified but is not reached in full in the literature. Accordingly, potential design strategies and issues related to the development of new membrane materials with improved scale resistance are discussed, and future research needs are proposed (Tong et al. 2019).

Modification of the membrane surface and development of a new material can be an effective strategy to reduce the scaling of the membrane (Baoxia et al. 2010, Du et al. 2018, Kang et al. 2012). The methodology for predicting scaling by membrane distillation (MD), which considers the thermodynamics, kinetics and mechanics of the liquid, was developed and experimentally confirmed using calcium sulfate (Rahman 2013, Warsinger et al. 2017, Kavitskaya et al. 2000).

This review describes in detail the various contaminants and contamination mechanisms in the membrane distillation process, their possible mitigation and control methods, and characterization strategies that can help in understanding and minimizing the contamination problem (Tijing et al. 2015, Litynska et al. 2019).

Despite the significant amount of research and publications, the development of effective scale stabilizers is very important and relevant.

Thus, the development of methods for effective stabilization water treatment will reduce corrosion and scale formation in heat exchange equipment, as well as allows switching to closed systems of water consumption and rational use of water (Gomelya et al. 2020, Vorobyova et al. 2019). The development of scientific bases of resource-saving technologies will increase the level of ecological safety of objects, region and country.

\section{MATERIALS AND METHODS}

The processes were studied using a Filmtec TW30-1812-50 low pressure reverse osmosis membrane cassette. A low-mineralized solution, similar in composition to the water from Toretsk: $\left(\mathrm{H}=10.3 \mathrm{mg}\right.$-eq $/ \mathrm{dm}^{3}, \mathrm{C}\left(\mathrm{Ca}^{2+)}=3.4 \mathrm{mg}\right.$-eq $/ \mathrm{dm}^{3}$, $\mathrm{C}\left(\mathrm{Mg}^{2+)}=6.9 \mathrm{mg}\right.$-eq $/ \mathrm{dm}^{3}, \mathrm{~L}=4.6 \mathrm{mg}-\mathrm{eq} / \mathrm{dm}^{3}$, $\mathrm{C}\left(\mathrm{SO}_{4}{ }^{2-}\right)=15.0 \mathrm{mg}$-eq $/ \mathrm{dm}^{3}, \mathrm{C}\left(\mathrm{Cl}^{-}\right)=3.1 \mathrm{mg}$ $\mathrm{eq} / \mathrm{dm}^{3}, \mathrm{pH}=8.47$ ) was used as a medium. After filtering the solution, the turbidity decreased from $50.0 \mathrm{mg} / \mathrm{dm}^{3}$ to $0.0 \mathrm{mg} / \mathrm{dm}^{3}$; chromaticity - from 90.0 degrees $\mathrm{Pt} / \mathrm{Co}$ up to 22.0 degrees $\mathrm{Pt} / \mathrm{Co}$.

The process of reverse osmosis desalination of water was carried out using $10 \mathrm{dm}^{3}$ of model solution. By means of a pump, water was fed into a cassette with a reversed osmosis membrane. The concentrate was returned to the container 
with the initial solution, the permeate was taken in a separate container. The pressure in the system was maintained by a valve that regulates the selection of concentrate. After sampling each $\mathrm{dm}^{3}$ of purified solution, the permeate and concentrate were analyzed for chlorides, sulfates, hardness ions and alkalinity was determined. The degree of permeate selection was varied from 10 to $90 \%$. Sulfates were determined by using the photometric method, chlorides with the Moore method, whereas alkalinity and hardness by means standard methods.

Membrane performance (transmembrane flow rate) was determined by the formula:

$$
J=\frac{\Delta V}{S \cdot \Delta t}
$$

where: $\Delta V$ is the volume of permeate $\left(\mathrm{dm}^{3}\right)$ that passed through the membrane with area $S$ $\left(\mathrm{m}^{2}\right)$ during the sampling $\Delta t(\mathrm{~h})$.

When conducting the studies to assess the effectiveness of scale stabilizers a thermostat was used. The samples of $100 \mathrm{ml}$ were kept at a temperature of $60^{\circ} \mathrm{C}$ for 6 hours. The choice of temperature is due to the fact that real water circulation systems operate at a temperature of 40-60 ${ }^{\circ} \mathrm{C}$. As inhibitors were used hydrolyzed polyacrylamide (HPAA) after ozonation of its $5 \%$ solution for 1 hour, hydrolyzed polyacrylonitrile (HPAN) after ozonation of $5 \%$ solution for 1 hour and HPAN after sonication of $1 \%$ solution for 20 minutes. Improvement of the efficiency of reagents is achieved by ozonation or physical modification with low-frequency sound waves (USB). Doses of these reagents were $0.5-15.0 \mathrm{mg} / \mathrm{dm}^{3}$. After cooling, the samples were filtered, and the residual water hardness was determined.

The stabilizing effect was calculated by the formula:

$$
\begin{gathered}
S E=\left(1-\frac{\Delta H_{i}}{\Delta H}\right) \cdot 100 \% \\
\Delta H_{i}=H-H_{i} \\
\Delta H=H-H_{\text {res }}
\end{gathered}
$$

The anti-scale effect was calculated by the formula:

$$
A S E=\frac{H_{i}}{H} \cdot 100 \%
$$

where: $S E$-stabilizing effect, \%; $A S E$ - anti-scale effect, $\Delta H$ - reduction of hardness in the blank experiment, mg-eq $/ \mathrm{dm}^{3} ; \Delta H_{i}-$ reduction of hardness in the experiment with a scale inhibitor, mg-eq/ $/ \mathrm{dm}^{3} ; H_{\text {res }}-$ residual hardness in the blank, mg-eq $/ \mathrm{dm}^{3} ; H_{\mathrm{i}}-$ residual hardness in the sample with a stabilizer, $\mathrm{mg}$-eq $/ \mathrm{dm}^{3}$.

\section{RESULTS AND DISCUSSION}

Improving the quality of used water reduces its discharge to purge systems, which reduces the water intake from natural sources and discharge of mineralized water into reservoirs, which leads to their pollution. Development of effective scale stabilizers allows developing the resource-saving technologies of water use.

The methods of combating salt deposits are aimed at preventing the loss of salts or removing the formed salt deposits (Amjad and Demadis 2015, Chauhan et al. 2015). The classification of these methods is presented in Figure 1.

There are several impurities that significantly reduce the service life of membranes (Ruengruehan et al. 2020, Gomelya et al. 2014). The first group includes insoluble solids, suspended and colloidal particles. The second group includes the compounds, the presence of which in water leads to the formation of solid inclusions (Kassymbekov et al. 2021, Sevostianov et al. 2021). It is possible to remove the substances belonging to the first group at the expense of mechanical methods, besides preliminary clarification of water on the filter leads to increase in productivity of a membrane (Polyakov et al. 2019). When filtering the model solution at a pressure of $0.3 \mathrm{MPa}$, the productivity of the installation decreases gradually (Fig. 2, Table 1) as the mineralization of the concentrate increases with increasing degree of selection of permeate. Pre-clarification of water (curve 2) leads to an increase in installation productivity and has little effect on its selectivity for chlorides, sulfates, hardness ions and hydrocarbons.

In this case, the decrease in membrane productivity with increasing degree of permeate selection is due to the increase in osmotic pressure along with the salt content in the concentrate. However, in general, the decrease in the productivity of membrane installations by $95-97 \%$ is determined by the contamination of the membrane surface and only by $3-5 \%$ by the compaction of their capillary-porous structure. Fundamentally dangerous compounds that promote 


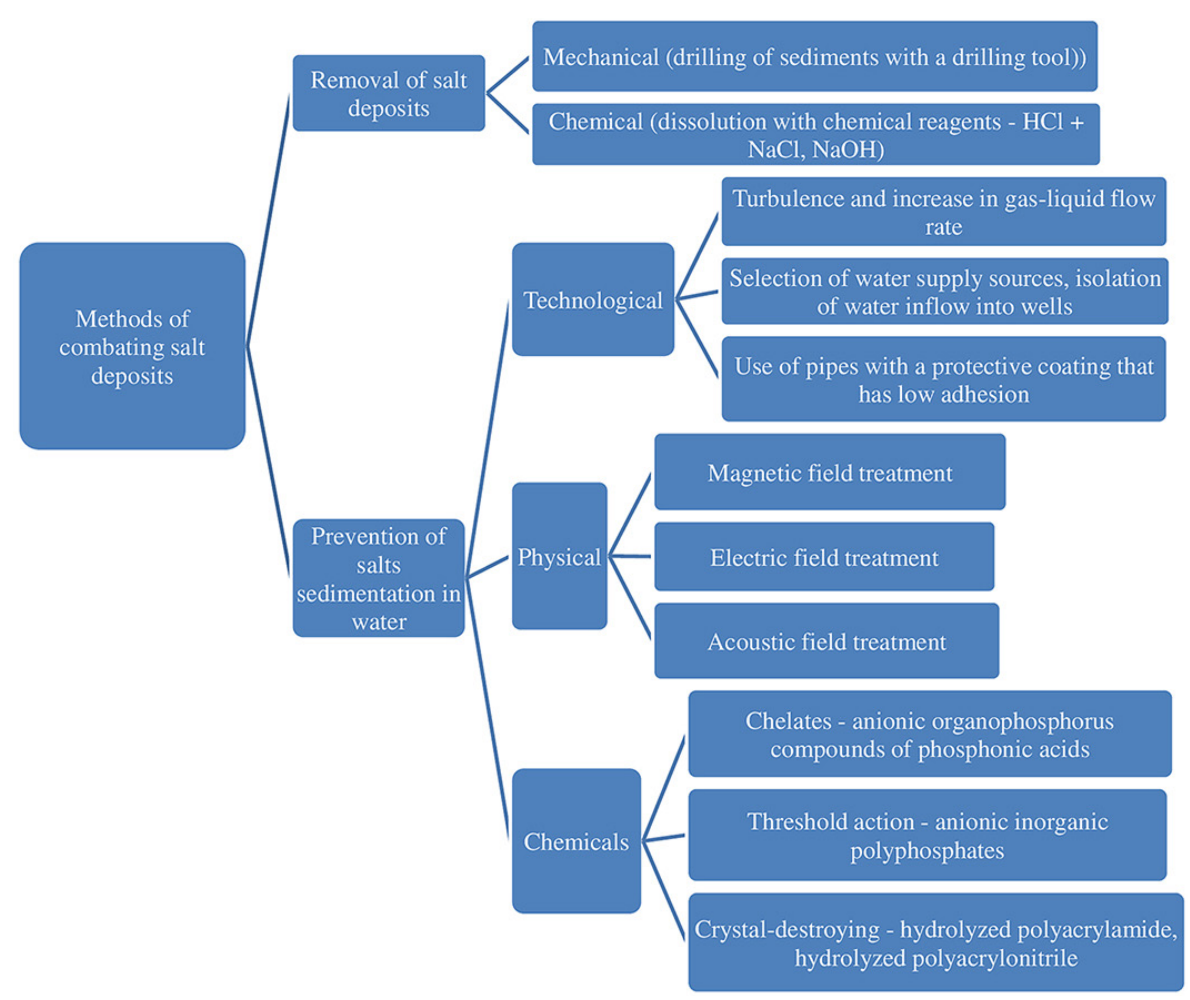

Figure 1. Classification of methods of combating salt deposits

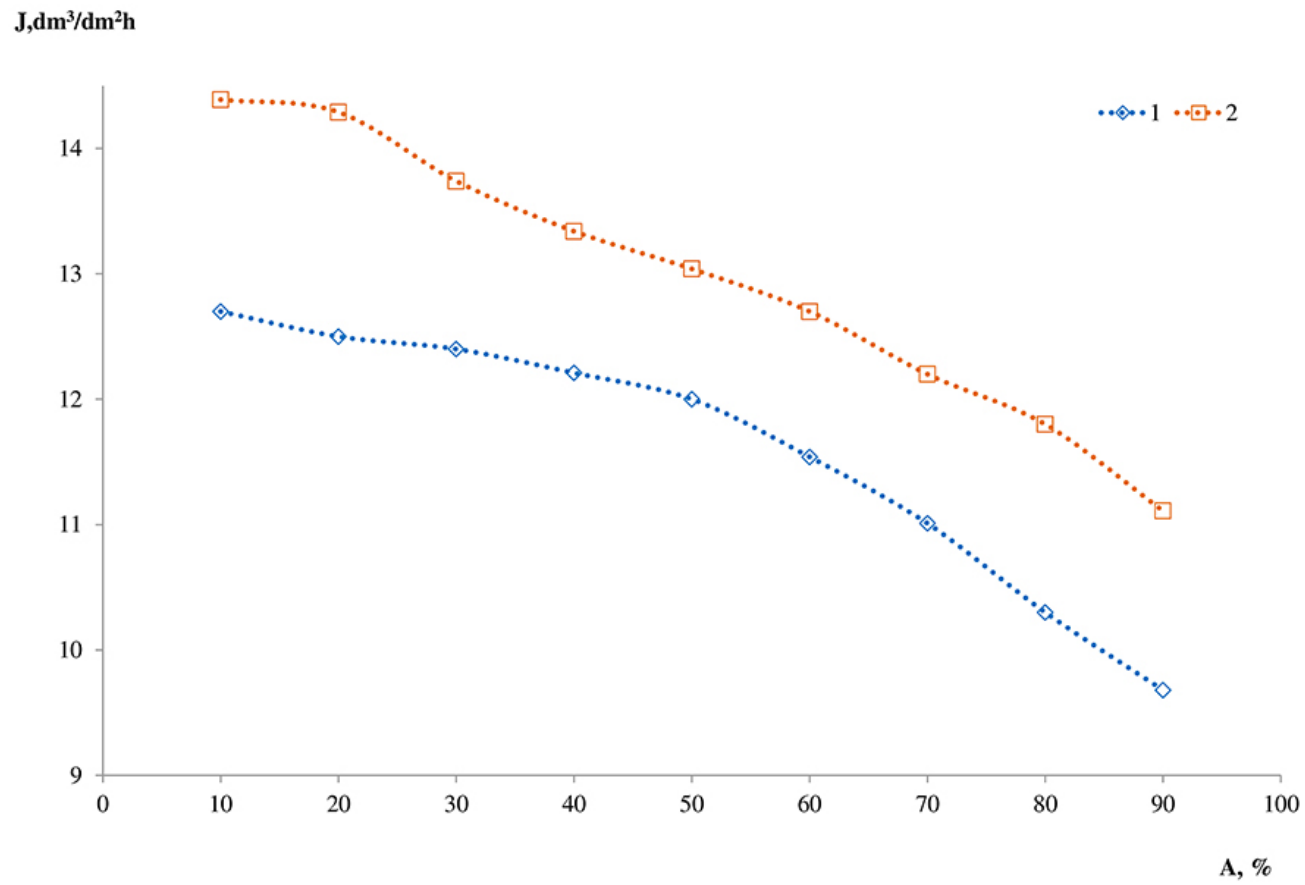

Figure 2. The dependence of the performance of the reverse osmosis filter on the degree of selection of permeate during desalination of the model solution

sedimentation on membranes include hardness salts - compounds of calcium and magnesium in the form of carbonates, bicarbonates and sulfates (Sharma et al. 2020). One of the promising ways to prevent membrane contamination is the adding of antiscalant (sedimentation inhibitor).
Since under the actual conditions at room temperature, the carbonate deposits on the membrane are formed rather slowly, the effectiveness of antiscalants was assessed using the express method. It was based on determining the stability of concentrates of reverse osmosis water purification. 
Table 1. Dependence of membrane selectivity on the degree of permeate selection during filtration of model solution (I) and solution after filtration (II)

\begin{tabular}{|c|c|c|c|c|c|c|}
\hline \multirow{3}{*}{ Z, \% } & \multicolumn{6}{|c|}{$R, \%$} \\
\hline & \multicolumn{3}{|c|}{1} & \multicolumn{3}{|c|}{ II } \\
\hline & Hardness & $\mathrm{SO}_{4}^{2-}$ & $\mathrm{Cl}^{-}$ & Hardness & $\mathrm{SO}_{4}^{2-}$ & $\mathrm{Cl}^{-}$ \\
\hline 10 & 99.66 & 99.49 & 91.13 & 99.69 & 99.21 & 91.14 \\
\hline 20 & 99.31 & 99.22 & 89.92 & 99.71 & 99.09 & 91.96 \\
\hline 30 & 99.31 & 99.09 & 88.99 & 99.70 & 98.98 & 90.97 \\
\hline 40 & 99.33 & 99.07 & 89.33 & 99.71 & 98.99 & 90.15 \\
\hline 50 & 99.45 & 99.14 & 89.67 & 99.71 & 99.14 & 90.11 \\
\hline 60 & 99.57 & 99.23 & 90.69 & 99.72 & 99.23 & 90.15 \\
\hline 70 & 99.62 & 99.33 & 90.98 & 99.77 & 99.36 & 90.72 \\
\hline 80 & 99.74 & 99.42 & 92.21 & 99.82 & 99.53 & 92.61 \\
\hline 90 & 99.73 & 99.63 & 94.29 & 99.87 & 99.60 & 94.63 \\
\hline
\end{tabular}

Studies were performed in the presence of an antiscalant and without an antiscalant. During the desalination of the model solution at a sampling rate of $\sim 80 \%$, a concentrate is formed with the following characteristics: $\mathrm{H}=50.0 \mathrm{mg}-\mathrm{eq} / \mathrm{dm}^{3}$, A $=23.0 \mathrm{mg}-\mathrm{eq} / \mathrm{dm}^{3}, \mathrm{SO}_{4}{ }^{2-}=75.0 \mathrm{mg}-\mathrm{eq} / \mathrm{dm}^{3}, \mathrm{Cl}^{-}=$ $15.0 \mathrm{mg}-\mathrm{eq} / \mathrm{dm}^{3}, \mathrm{pH}=8.71$.

The use of highly mineralized waters leads to intensive sedimentation, especially at elevated temperatures, resulting in the failure of pipelines and equipment. Therefore, it is necessary to use sediment inhibitors.

The effectiveness of scale inhibitors depends on the quality of the source water. This water is unstable to scaling, because when heated, the hardness decreases from 50 to $38 \mathrm{mg}$-eq $/ \mathrm{dm}^{3}$ at a temperature of $60^{\circ} \mathrm{C}$.

If the polyphosphates are used long-term, the hydrolysis to orthophosphates occurs. As a result of this polyphosphates lose their activity. In addition, phosphorus is a biogenic element that leads to increased biofouling in buildings and communications. HPAN is a stable substance, so it does not decompose chemically in water at temperatures in the range of $0-100{ }^{\circ} \mathrm{C}$. This reagent is an effective inhibitor of scaling of highly mineralized waters at temperatures up to $100{ }^{\circ} \mathrm{C}$ when used in concentrations of $0.5-15 \mathrm{mg} / \mathrm{dm}^{3}$.
Evaluation of the effectiveness of sediment inhibitors was carried out by changing the hardness of mineralized water when heated to a temperature of $60{ }^{\circ} \mathrm{C}$ in the presence of inhibitors. The results are shown in Tables 2, 3 .

The stabilizing effect of HPAN and HPAA without treatment in highly mineralized waters at a dose of $1-15 \mathrm{mg} / \mathrm{dm}^{3}$ is $39-43 \%$. Ultrasonic or ozonation treatment of these reagents can increase the stabilizing and anti-scale effects.

As it can be seen from Table 3, the HPAN in concentrations of $0.5-5.0 \mathrm{mg} / \mathrm{dm}^{3}$ appeared ineffective; however, an increase of a dose to 5-15 $\mathrm{mg} / \mathrm{dm}^{3}$ showed rather high stability of water in relation to scaling.

The stabilizing effect when using HPAA reached $16.7 \%$ at a dose of $1 \mathrm{mg} / \mathrm{dm}^{3}$ and $45.8 \%$ at a dose of $2 \mathrm{mg} / \mathrm{dm}^{3}$. When increasing the dose of HPAA to $5.0 \mathrm{mg} / \mathrm{dm}^{3}$, this inhibitor provided $100 \%$ water stability (Fig. 3 ).

HPAN at a concentration of $5 \mathrm{mg} / \mathrm{dm}^{3}$ for highly mineralized waters provides a stabilizing effect of $99.8 \%$, and the anti-scale effect of 99.2\% (Fig. 4). Therefore, the obtained results indicate the potential of the selected reagents as stabilizers of scale formation.

Table 2. The dependence of the stability of the concentrate on the dose of HPAA after ozonation at $60{ }^{\circ} \mathrm{C}$

\begin{tabular}{|c|c|c|c|c|}
\hline Доза, мг/дм ${ }^{3}$ & $\mathrm{H}, \mathrm{mg}-\mathrm{eq} / \mathrm{dm}^{3}$ & $\mathrm{H}_{\text {res. }}, \mathrm{mg}-\mathrm{eq} / \mathrm{dm}^{3}$ & $\Delta \mathrm{H}, \mathrm{mg}$-eq $/ \mathrm{dm}^{3}$ & CE, \% \\
\hline 0 & 50.0 & 38.0 & 12.0 & - \\
\hline 0.5 & 50.0 & 39.0 & 11.0 & 8.3 \\
\hline 1.0 & 50.0 & 40.0 & 10.0 & 16.7 \\
\hline 2.0 & 50.0 & 43.5 & 6.5 & 45.8 \\
\hline 5.0 & 50.0 & 49.9 & 0.0 & 99.2 \\
\hline
\end{tabular}


Table 3. The dependence of the stability of the concentrate on the dose of HPAN at $60{ }^{\circ} \mathrm{C}$

\begin{tabular}{|c|c|c|c|c|}
\hline Доза, мг/дм³ & $\mathrm{H}, \mathrm{mg}-\mathrm{eq} / \mathrm{dm}^{3}$ & $\mathrm{H}_{\text {res }}, \mathrm{mg}-\mathrm{eq} / \mathrm{dm}^{3}$ & $\Delta \mathrm{H}, \mathrm{mg}-\mathrm{eq} / \mathrm{dm}^{3}$ & CE, \% \\
\hline 0 & 50.0 & 38.0 & 12.0 & - \\
\hline \multicolumn{5}{|c|}{ HPAN after sonication } \\
\hline 0.5 & 50.0 & 39.5 & 10.5 & 12.5 \\
\hline 1.0 & 50.0 & 41.5 & 8.5 & 29.2 \\
\hline 2.0 & 50.0 & 42.0 & 8.0 & 33.3 \\
\hline 5.0 & 50.0 & 42.5 & 7.5 & 37.5 \\
\hline 8.0 & 50.0 & 43.4 & 6.6 & 45.0 \\
\hline 10.0 & 50.0 & 44.5 & 5.45 & 54.2 \\
\hline 12.0 & 50.0 & 45.6 & 4.4 & 63.3 \\
\hline 15.0 & 50.0 & 46.7 & 3.3 & 72.5 \\
\hline \multicolumn{5}{|c|}{ HPAN after ozonation } \\
\hline 0.5 & 50.0 & 41.0 & 9.0 & 25.0 \\
\hline 1.0 & 50.0 & 42.0 & 8.0 & 33.3 \\
\hline 2.0 & 50.0 & 43.5 & 6.5 & 45.8 \\
\hline 5.0 & 50.0 & 44.0 & 6.0 & 50.0 \\
\hline 8.0 & 50.0 & 45 & 5 & 58.3 \\
\hline 10.0 & 50.0 & 45.8 & 4.2 & 65.0 \\
\hline 12.0 & 50.0 & 46.4 & 3.6 & 70.0 \\
\hline 15.0 & 50.0 & 47.1 & 2.9 & 75.8 \\
\hline
\end{tabular}

\section{CONCLUSIONS}

It was established that pre-purification of the model solution before reverse osmosis desalination helps increase the productivity of the membrane and has little effect on its selectivity for chlorides, sulfates, hardness ions and bicarbonates. Evaluation of the efficiency of using HPAN and HPAA as a stabilizer of scale formation for concentrates of reverse osmotic desalination of water (highly mineralized waters) was performed. HPAA at a concentration of $5 \mathrm{mg} / \mathrm{dm}^{3}$ for the waters with $\mathrm{H}=50 \mathrm{mg}$-eq $/ \mathrm{dm}^{3}$ at $\mathrm{T}=60^{\circ} \mathrm{C}$ and $t=6 \mathrm{~h}$ provides a stabilizing effect at the level

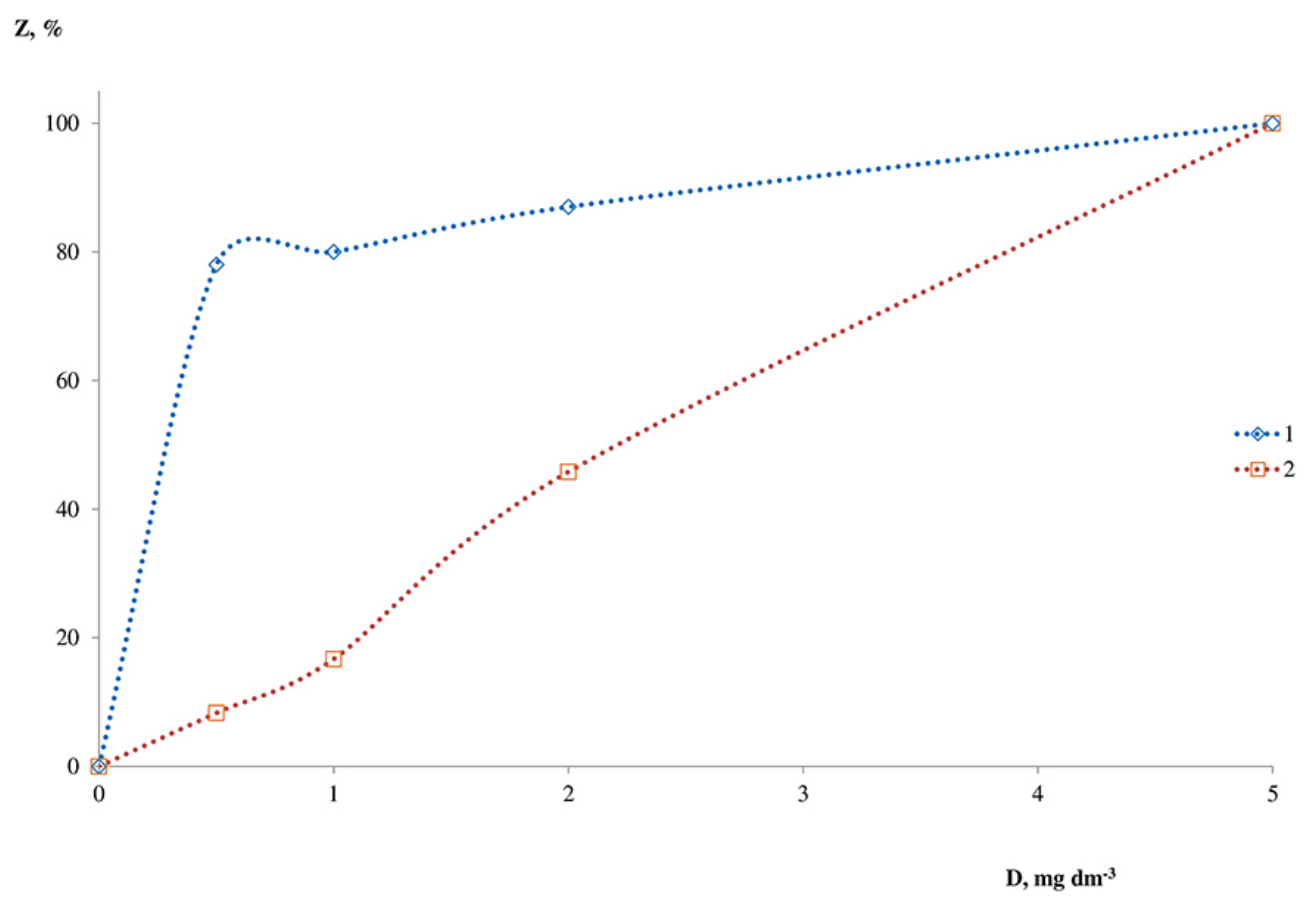

Figure 3. The effect of HPAA dose at $60{ }^{\circ} \mathrm{C}$ on water stability; 1 - anti-scale effect; 2 - stabilizing effect 


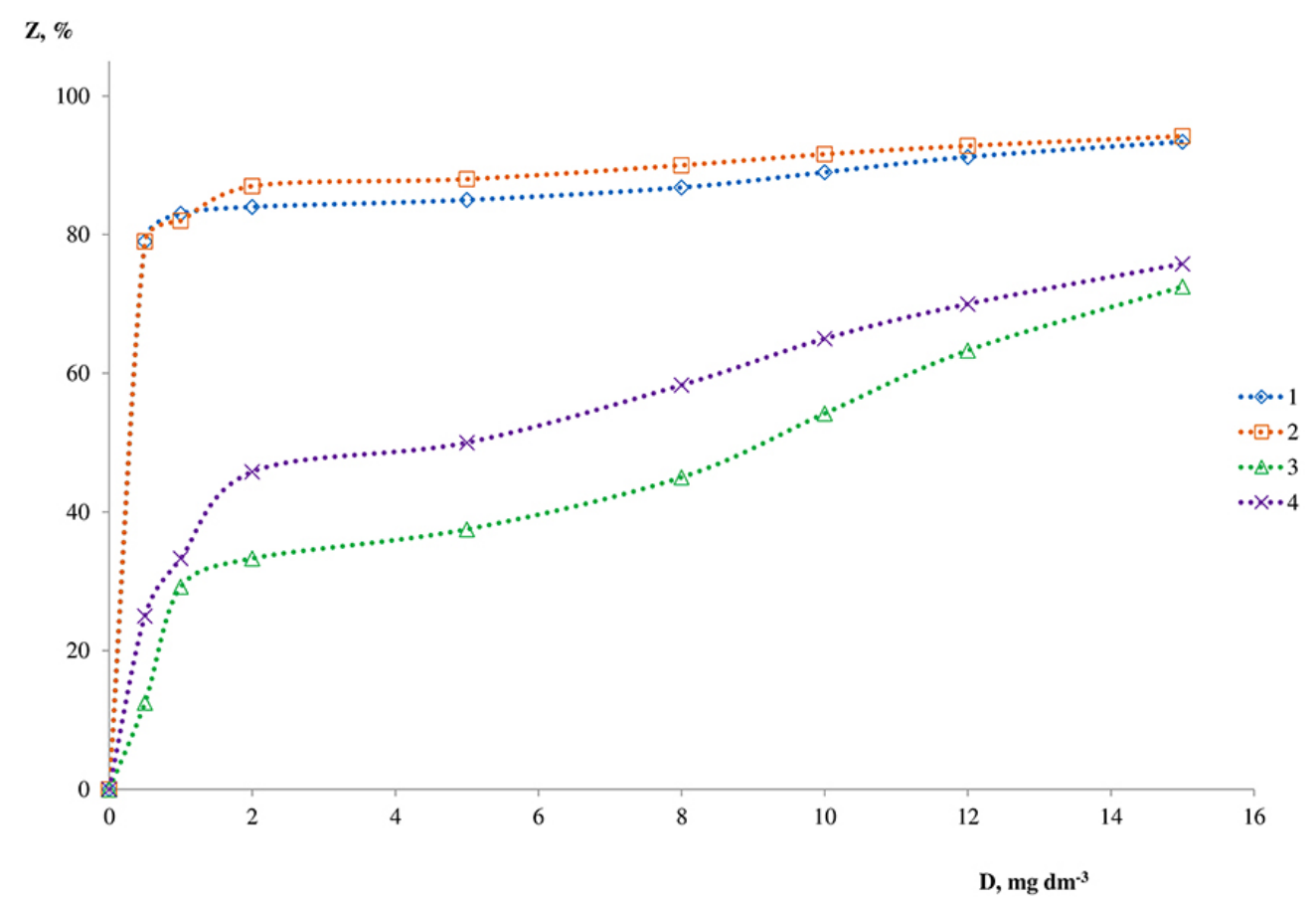

Figure 4. The effect of a dose of HPAN at $60{ }^{\circ} \mathrm{C}$ on water stability; 1,2 - anti-scale effect; 3, 4- stabilizing effect; 1, 3-HPAN after ultrasound; 2, 4 - HPAN after ozonation

of $37.5-50 \%$, and the anti-scale effect at $85-88 \%$. With increasing reagent concentration to $15 \mathrm{mg} /$ $\mathrm{dm}^{3}$, the anti-scale effect reaches $72.5-75.8 \%$ and the stabilizing effect $93.4-94.2 \%$. Direct proportion of residual hardness to dose was found for HPAN. HPAN was shown to be a highly effective scale inhibitor at a dose of $5.0 \mathrm{mg} / \mathrm{dm}^{3}$, with a stabilizing effect of $99.8 \%$.

\section{REFERENCES}

1. Abualhaija M., Mohammad A.H. 2021. Assessing Water Quality of Kufranja Dam (Jordan) for Drinking and Irrigation: Application of the Water Quality Index. J. Ecol. Eng., 22(9), 159-175. DOI: $10.12911 / 22998993 / 141531$

2. Amjad Z., Demadis K.D. 2015. Mineral Scales and Deposits: Scientific and Technological Approaches. Elsevier, Amsterdam.

3. Ang W., Mohammad A., Benamor A., Hilal N., Leo C. 2016. Hybrid coagulation-NF membrane process for brackish water treatment: effect of antiscalant on water characteristics and membrane fouling. Desalination, 393, 144-150. DOI: 10.1016/j. desal.2016.01.010

4. Antony A., Low J. H., Gray S., Childress A. E., LeClech P., Leslie G. 2011. Scale formation and control in high pressure membrane water treatment systems: A review. Journal of Membrane Science, 383(1-2), 1-16. DOI: 10.1016/j.memsci.2011.08.054
5. Ashfaq M.Y., Al-Ghouti M.A., Qiblawey H., Rodrigues D.F., Hu Y., Zouari N. 2019. Isolation, identification and biodiversity of antiscalant degrading seawater bacteria using MALDI-TOF-MS and multivariate analysis. Sci. Total Environ., 656, 910-920. DOI: 10.1016/j.scitotenv.2018.11.477

6. Baoxia M.I., Elimelech M. 2010. Gypsum scaling and cleaning in forward osmosis: Measurements and mechanisms. Environmental Science and Technology, 44(6), 2022-2028. DOI: 10.1021/es903623r

7. Biggs E.M., Bruce E., Boruff B., Duncan J.M.A., Horsley J., Pauli N., McNeill K., NeefA., Van Ogtrop F., Curnow J., Haworth B., Duce S., Imanari Y. 2015. Sustainable development and the water-energy-food nexus: a perspective on livelihoods. Environ Sci Policy, 4, 389-397. DOI: 10.1016/j.envsci.2015.08.002

8. Chauhan K., Sharma P., Chauhan G.S. 2015. Chapter 29 - Removal/Dissolution of Mineral Scale Deposits. Scientific and Technological Approaches, 701720. DOI: 10.1016/B978-0-444-63228-9.00029-2

9. Chaussemier M., Pourmohtasham E., Gelus D., Pécoul N., Perrot H., et al. 2015. State of art of natural inhibitors of calcium carbonate scaling. A review article. Desalination, Elsevier, 356, 47-55. DOI: 10.1016/j.desal.2014.10.014

10. Chen L., Chen Z., Wang Y., Mao Y., Cai Z. 2021. Effective treatment of leachate concentrate using membrane distillation coupled with electrochemical oxidation. Separation and Purification Technology, 267. DOI: 10.1016/j.seppur.2021.118679

11. Chesters S.P. 2009. Innovations in the inhibition and cleaning of reverse osmosis membrane scaling 
and fouling. Desalination, 238(1-3), 22-29. DOI: 10.1016/j.desal.2008.01.031.

12. Cohen Y., Semiat R., Rahardianto A. 2017. A Perspective on Reverse Osmosis Water Desalination: Quest for Sustainability. AIChE Journal, 63 (6), 1771-1784. DOI: 10.1002/aic

13. Croué J., Manes C.D., Aubry C., Khan M.T. 2013. Source water quality shaping different fouling scenarios in a full-scale desalination plant at the Red Sea. Water Res., 47(2), 558-568. DOI: 10.1016/j. watres.2012.10.017

14. Da'na D.A., Al-Ghouti M.A., Zouari N., Qiblawey H., Ashfaq M.Y. 2020. Investigating the effect of temperature on calcium sulfate scaling of reverse osmosis membranes using FTIR, SEM-EDX and multivariate analysis. Sci. Total Environ., 703, 134726. DOI: $10.1016 /$ j.scitotenv.2019.134726

15. DiGiulio D.C., Jackson R.B. 2016. Impact to underground sources of drinking water and domestic wells from production well stimulation and completion practices in the Pavillion, Wyoming, Field. Environ Sci Technol., 50, 4524-4536. DOI: 10.1021/ acs.est. 5 b0 4970

16. Du X., Zhang Z., Carlson K.H., Lee J., Tong T. 2018. Membrane fouling and reusability in membrane distillation of shale oil and gas produced water: Effects of membrane surface wettability. J. Membr. Sci., 567, 199-208. DOI: 10.1016/j. memsci.2018.09.036

17. Filloux E., Wang J., Pidou M., Gernjak W., Yuan Z. 2015. Biofouling and scaling control of reverse osmosis membrane using one-step cleaningpotential of acidified nitrite solution as an agent. J. Membr. Sci., 495, 276-283. DOI: 10.1016/j. memsci.2015.08.034

18. Golovesov V.A., Pervov A.G., Smirnov A.D. 2021. Investigation of scaling mechanism on reverse osmosis membranes using fluorescent antiscalant. Paper presented at the IOP Conference Series: Materials Science and Engineering, , 1030(1). DOI: 10.1088/1757-899X/1030/1/012064

19. Gomelya M.D., Trus I.M., Radovenchyk I.V. 2014. Influence of stabilizing water treatment on weak acid cation exchange resin in acidic form on quality of mine water nanofiltration desalination. Naukovyi Visnyk Natsionalnoho Hirnychoho Universytetu, (5), 100-105.

20. Gomelya N., Trus I., Stepova O., Kyryliuk O., Ivanenko O., Khomenko A. 2020. Devising a corrosion inhibitor for steel St-37-2 in wateroil mixture. Eastern-European Journal of Enterprise Technologies, 2/6 (104), 28-33. DOI: 10.15587/1729-4061.2020.199849

21. He F., Sirkar K.K., Gilron J. 2009. Effects of antiscalants to mitigate membrane scaling by direct contact membrane distillation. Journal of
Membrane Science, 345(1-2), 53-58. DOI: 10.1016/j.memsci.2009.08.021

22. Kang G., Liu Z., Yu H., Cao Y. 2012. Enhancing antifouling property of commercial polyamide reverse osmosis membrane by surface coating using a brush-like polymer containing poly (ethylene glycol) chains. Desalination and Water Treatment. 37(1-3), 139-145. DOI: $10.1080 / 19443994.2012 .661265$

23. Kassymbekov Z., Akmalaiuly K., Kassymbekov G. 2021. Application of Hydrocyclones to Improve Membrane Technologies for Urban Wastewater Treatment. Journal of Ecological Engineering. 22(4), 148-155. DOI: 10.12911/22998993/134043

24. Kavitskaya A., Knyazkova T., Maynarovich A. 2000. Reverse osmosis of concentrated calcium sulphate solutions in the presence of iron (III) ions using composite membranes. Desalination, 132(1-3), 281-286. DOI: 10.1016/S0011-9164(00)00161-2

25. Khan M.T., De O., Manes C., Aubry C., Gutierrez L., Croue J.P. 2013. Kinetic study of seawater reverse osmosis membrane fouling. Environ. Sci. Technol. 47(19), 10884-10894. DOI: 10.1021/ es402138e

26. Kucera J. 2019. Biofouling of polyamide membranes: fouling mechanisms, current mitigation and cleaning strategies, and future prospects. Membranes, 9(9), 111, DOI: 10.3390/membranes9090111

27. Li C., Yang Q., Lu S., Liu Y. 2021. Adsorption and mechanism study for phosphonate antiscalant HEDP removal from reverse osmosis concentrates by magnetic La/Zn/Fe3O4@PAC composite. Colloids and Surfaces A: Physicochemical and Engineering Aspects, 613 DOI: 10.1016/j.colsurfa.2020.126056

28. Litynska M., Antoniuk R., Tolstopalova N., Astrelin I. 2019. Ferric Oxyhydroxide as Fouling Prevention Reagent for Low-Pressure Membranes. J. Ecol. Eng., 20(3), 77-84. DOI: 10.12911/22998993/99736

29. Mangal M.N., Salinas-Rodriguez S.G., Dusseldorp J., Kemperman A.J.B., Schippers J.C., Kennedy M.D., van der Meer W.G.J. 2021. Effectiveness of antiscalants in preventing calcium phosphate scaling in reverse osmosis applications. Journal of Membrane Science, 623, DOI: 10.1016/j. memsci.2021.119090

30. Mi B., Elimelech M. 2013. Silica scaling and scaling reversibility in forward osmosis. Desalination 312, 75-81. DOI: 10.1016/j.desal.2012.08.034

31. Miller S., Shemer H., Semiat R. 2015. Energy and environmental issues in desalination. Desalination, 366, 2-8. DOI: 10.1016/j.desal.2014.11.034

32. Pervov A.G., Andrianov A.P. 2017. Assessment of the effectiveness of new "green" scale inhibitors used in reverse-osmosis seawater desalination. Petroleum Chemistry, 57, 139-152. 
33. Polyakov V., Kravchuk A., Kochetov G., Kravchuk O. 2019. Clarification of aqueous suspensions with a high content of suspended solids in rapid sand filters. Eureca: Physics and engineering, 1(20), 28-35. DOI: $10.21303 / 2461-4262.2019 .00827$

34. Popov K., Oshchepkov M., Afanas'eva E., Koltinova E., Dikareva Y., Rönkkömäki H. 2019. A new insight into the mechanism of the scale inhibition: DLS study of gypsum nucleation in presence of phosphonates using nanosilver dispersion as an internal light scattering intensity reference. Collid Surf. A Physicochem. Eng. Asp., 560, 122-129. DOI: 10.1016/j.colsurfa.2018.10.015

35. Pramanik B.K., Gao Y., Fan L., Roddick F.A., Liu Z. 2017. Antiscaling effect of polyaspartic acid and its derivative for RO membranes used for saline wastewater and brackish water desalination. Desalination, 404, 224-229. DOI: 10.1016/j.desal.2016.11.019.

36. Qiang X., Sheng Z., Zhang H. 2013. Study on scale inhibition performances and interaction mechanism of modified collagen. Desalination, 309, 237-242. DOI: 10.1016/j.desal.2012.10.025

37. Radovenchyk I., Trus I., Halysh V., Krysenko T.,Chuprinov E., Ivanchenko A. 2021. Evaluation of Optimal Conditions for the Application of Capillary Materials for the Purpose of Water Deironing. Ecol. Eng. Environ. Technol., 22(2), 1-7. DOI: $10.12912 / 27197050 / 133256$

38. Rahman F. 2013. Calcium sulfate precipitation studies with scale inhibitors for reverse osmosis desalination. Desalination, 319, 79-84. DOI: 10.1016/j. desal.2013.03.027

39. Rashed E.A., Elshafei M.M., Hiekl M.A., Matta M.E., Naguib K.M. 2016. On-line dosing of Ammonium Biflouride for reduction of silica scaling on RO membranes. HBRC Journal, 12(2), 205-211. DOI: 10.1016/j.hbrcj.2014.10.001

40. Remeshevska I., Trokhymenko G., Gurets N., Stepova O., Trus I., Akhmedova V. 2021. Study of the Ways and Methods of Searching Water Leaks in Water Supply Networks of the Settlements of Ukraine Ecol. Eng. Environ. Technol., 22(4), 14-21. DOI: $10.12912 / 27197050 / 137874$

41. Ruengruehan K., Kang S., Sanphoti N., Khaodhiar S. 2020. Effect of Surfactant Properties on the Performance of Forward Osmosis Membrane Process. J. Ecol. Eng., 21(8), 10-17. doi. org/10.12911/22998993/127432

42. Sevostianov I., Ivanchuk Y.,Polishchuk J., Lutsyk V., Dobrovolska K., Smailova S., Wójcik W., Kalizhanova A. 2021. Development of the Scheme of the Installation for Mechanical Wastewater Treatment. J. Ecol. Eng., 22(1), 20-28. DOI: 10.12911/22998993/128693

43. Sharma A., Agnihotri B., Vemavarapu S., Gupta A. B. 2020. Chemistry of inorganic scaling in full-scale reverse osmosis plants treating brackish groundwater. Journal of Environmental Chemical Engineering, 8 (5), 104108. DOI: 10.1016/j. jece.2020.104108

44. Shemer H., Hasson D., Semiat R. 2013. Review of the state of the art of antiscalant selection. In: Zahid Amjad, editor. Mineral Scales in Biological and Industrial Systems. Boca Raton, FL: CRC Press, 227-256.

45. Sweity A., Oren Y., Ronen Z., Herzberg M. 2013. The influence of antiscalants on biofouling of RO membranes in seawater desalination. Water Res., 47(10), 3389-3398. DOI: 10.1016/j.watres.2013.03.042

46. Tijing L.D., Woo Y.C., Choi J., Lee S., Kim S., Shon H.K. 2015. Fouling and its control in membrane distillation-A review. Journal of Membrane Science, 475, 215-244. DOI: 10.1016/j.memsci.2014.09.042

47. Tong T., Wallace A.F., Zhao S., Wang Z. 2019. Mineral scaling in membrane desalination: Mechanisms, mitigation strategies, and feasibility of scaling-resistant membranes. Journal of Membrane Science, 579, 52-69. DOI: 10.1016/j. memsci.2019.02.049

48. Trus I.M., Fleisher H.Y., Tokarchuk V.V., Gomelya M.D., Vorobyova V.I. 2017. Utilization of the residues obtained during the process of purification of mineral mine water as a component of binding materials. Voprosy Khimii i Khimicheskoi Tekhnologii, (6), 104-109.

49. Trus I.M., Gomelya M.D. 2021. Desalination of mineralized waters using reagent methods. Journal of Chemistry and Technologies, 29(3), 417-424. DOI: $10.15421 /$ jchemtech.v29i3.214939

50. Trus I., Gomelya M. 2021. Effectiveness nanofiltration during water purification from heavy metal ions. Journal of Chemical Technology and Metallurgy, 56(3), 615-620.

51. Trus I., Radovenchyk I., Halysh V., Skiba M., Vasylenko I., Vorobyova V., Hlushko O., Sirenko L. 2019. Innovative Approach in Creation of Integrated Technology of Desalination of Mineralized Water. Journal of Ecological Engineering. 20(8), 107-113. DOI: $10.12911 / 22998993 / 110767$

52. Trus I., Gomelya N., Halysh V., Radovenchyk I., Stepova O., Levytska O. 2020. Technology of the comprehensive desalination of wastewater from mines. Eastern-European Journal of Enterprise Technologies, 3/6 (105), 21-27. DOI: 10.15587/1729-4061.2020.206443

53. Vorobyova V.I., Skiba M.I., Trus I.M. 2019. Apricot pomaces extract (prunus armeniaca 1.) as a highly efficient sustainable corrosion inhibitor for mild steel in sodium chloride solution. International Journal of Corrosion and Scale Inhibition, 8(4), 1060-1083. DOI: $10.17675 / 2305-6894-2019-8-4-15$ 
54. Warsinger D.M., Tow E.W., Swaminathan J., Lienhard V.J.H. 2017. Theoretical framework for predicting inorganic fouling in membrane distillation and experimental validation with calcium sulfate. Journal of Membrane Science, 528, 381-390. DOI: 10.1016/j.memsci.2017.01.031

55. Yelemanova A., Aliyarova M., Begimbetova A., Jangaskina A., Temirbekova M. 2021. The Use of Membrane Technologies of the CWTP to Obtain Quality Drinking Water J. Ecol. Eng., 22(8), 103110. DOI: $10.12911 / 22998993 / 140263$
56. Yelemanova A., Aliyarova M., Begimbetova A., Jangaskina A., Temirbekova M. The Use of Membrane Technologies of the CWTP to Obtain Quality Drinking Water. J. Ecol. Eng., 22(8), 103-110. DOI: $10.12911 / 22998993 / 140263$

57. Yin Y., Jeong N., Minjarez R., Robbins C.A., Carlson K.H., Tong T. 2021. Contrasting behaviors between gypsum and silica scaling in the presence of antiscalants during membrane distillation. Environmental Science and Technology, 55(8), 5335-5346. DOI: 10.1021/acs.est.0c07190 